\title{
HERNIA IN UNDESCENDED TESTIS MIMICKING AS SPIGELIAN HERNIA: STUDY OF TWO CASES WITH REVIEW OF LITERATURE
}

\author{
Hari Gopal Vyas ${ }^{1}$, Mohit Singh², Subrato Bhowmick³, Anuja Swami4, Vimal Bhandari5, Pawan Tiwari ${ }^{6}$
}

\section{HOW TO CITE THIS ARTICLE:}

Hari Gopal Vyas, M ohit Singh, Subrato Bhowmick, Anuja Swami, Vimal Bhandari, Pawan Tiwari. "Hernia in undescended testis mimicking as spigelian hernia: study of two cas es with review of literature". Journal of Evolution of Medical and Dental Sciences 2013; Vol. 2, Issue 44, November 04; Page: 8603-8607.

\begin{abstract}
Occurrence of Spigelian Hernia is rare accounting for $0.12 \%$ of all ventral hernias ${ }^{1}$. It is most commonly reported in adults while pediatric cases are rare. Though the association of Spigelian-Cryptorchidism syndrome has been comprehensively reported in pediatric patients, the same has not been detailed so far for the adult patient population. We herein discuss two cases of Spigelian hernia, both adults in whom intra-operative exploration revealed associated ipsilateral undescended testis. Not only is the pre-operative diagnosis seldom if ever, the imaging studies may not be successful in differentiating the type of hernia ${ }^{2,3}$. Even in the present cases radiological studies were inconclusive and definitive diagnosis was only attained intra-operatively.
\end{abstract}

KEY WORDS: Undescended testis, Spigelian hernia, deep inguinal ring.

\section{CASES PRESENTATIONS:}

CASE ONE: A 62 years old male patient presented to the Outpatient department with the complaint of a large swelling over the right lower abdomen present for around 30 years. His bowel habits were normal and there were no urinary complaints. The patient did not have history of trauma. The patient was a chronic smoker for approximately forty years.

Clinical examination revealed a huge lump of about $26 \mathrm{X} 20 \mathrm{~cm}$, occupying the Right Iliac fossa and Right Lumbar region and encroaching Umbilical and Hypogastric region [Image-1]. The lump was oval shaped, soft and partially reducible with gargling sound. Cough impulse was also present. Percussion note were resonant and bowel sounds were present over the lump on auscultation. Genital examination revealed absence of Testis and cord structures on the right side. Per rectal examination revealed mild prostatomegaly. A clinical impression of spigelian hernia was made and USG of abdomen was advised. USG report suggested the probability of Spigelian hernia. CECT [Image-4] was also undertaken and the findings were in accordance with the USG result.

Operative intervention was thus planned. Intra-operatively it was found to be interparietal inguinal hernia. Careful exploration revealed the hernia sac coming out of very widely dilated DIR of about $4 \mathrm{~cm}$ diameter and extending forward superiorly and laterally as well as medially and downwards [Image-2,3]. Testis was intraabdominal and atrophic while the External inguinal ring was almost completely obstructed. The external oblique muscle and the aponeurosis were extremely thin [Image-2] and the hernial sac was lying in between external and internal oblique muscles. A long segment of small gut with the mesentery was found within the sac. Inferior epigastric vessels were identified just medial to the neck of the sac. A formal herniotomy, right orchidectomy and strengthening of the floor was subsequently done by preperitoneal placement of prolene mesh. Post operative recovery was uneventful and patient was discharged on the second postoperative day. He remained symptom free at follow up of six months. 
CASE TWO: A 73 yr old patient presented with the complaints of swelling left inguinal region for the last 25 years. Physical examination revealed presence of a large hernia which paradoxically was localized in the upward and lateral direction [Image-5]. There was also absence of testis on the left side along with Phimosis. Per Rectal examination showed prostatomegaly.

Patient was subsequently taken up for surgical repair. Intraoperatively a left inguinal hernia with the sac in the subcutaneous plane was found. Within the sac, loops of intestine were visible along with peristal sis. The left test is was rudimentary and was found lying loosely attached to wall of the sac. There was no difficulty in separating the sac from the skin or the testis. Sac was returned to abdominal cavity, orchidectomy was done and hernioplasty was done using prolene mesh. Circumcision was also done.

Post operative period was uneventful and patient was discharged on second postoperative day. He is doing well in follow up at two months.

REVIEW OF LITERATURE: The real reason of occurrence of hernia is a patent processus vaginalis and a variable gubernaculum testis with its main insertion into the bottom of future testis, though there may be other insertions. If the scrotal tail is maldeveloped, the hernia may course up to the inguinal canal and thereafter may take an entirely different course then going into scrotum. Also, if there is resistance to the descent of the sac, it may progresses further in different direction and plane and may become interparietal (as in our first case or even subcutaneous (second case). Although the exact mechanism of this co-existence of Spigelian hernia and ipsilateral undescended testis remains elusive, several studies have postulated about the underlying events giving rise to this association. According to a study 4 the ectopic testis drags down a processus vaginalis which subsequently opens up with increased intra-abdominal pressure thus producing a Spigelian hernia. On the other hand, Rushfeldt et $\mathrm{al}^{5}$ cited four congenital ipsilateral elements in causation of this association: a defect in the Spigelian fascia, a hernia sac containing testis, absence of gubernaculum and absence of inguinal canal. While the testis was found lying outside the sac ${ }^{4}$ like in our case, it was within the sac in other series ${ }^{5}$. In Macready's ${ }^{6}$ series of 129 cases in males, congenital displacements of the testis were present in $67.1 \%$ of the cases. While in another series ${ }^{7}$ of interstitial hernia in males, abnormally placed testis were present in $51.3 \%$ cases. That an ectopic testis is not the only etiological factor present, however is evidenced by the occurrence of interstitial hernia in males with normally descended testis ${ }^{8}$.

Lower and Hicken ${ }^{8}$ reported in their series, that the interparietal hernias among all inguinal hernias should be as frequent as $0.01-1.6 \%$. Three subtypes of interparietal hernia have been described viz. Pre-peritoneal (between peritoneum and transversalis fascia), interstitial (between transversalis fascia and transverse, internal oblique or external oblique muscles), and superficial (between external oblique and skin or within aponeuro sis of the inguinal region. In our first case it was the interstitial variety, which is most common of the three subtypes as reported ${ }^{8}$. The other case was subcutaneous in type which comprises $20 \%$.

The case of Spigelian hernia which was not encountered in our study is different. It is a protrusion of preperitoneal fat, peritoneal sac, or organs due to a congenital/acquired defect in the linea semilunaris 9,10 . The line of transition between muscle fibres and the aponeurosis of the transversus abdominis muscle and the lateral border of the rectus sheath defines the semilunar, or 
spigelian, zone. A lateral ventral hernia may occur anywhere through the semilunar zone from above the level of the umbilicus to the pubic symphysis ${ }^{11}$.

The widest portion of the spigelian fascia is the area where the semilunar line intersects the arcuate line of Douglas (the linea semicircularis). It is in this region, between the umbilicus and the arcuate line, where more than $90 \%$ of spigelian hernias are found. The rearrangement of muscle and fascial fibres at the intersection of the arcuate and semilunar lines is thought to cause an area of functional weakness that is predisposed to hernia formation. CT and ultrasound have been used as a radiological adjunct for diagnosis in doubtful cases $12,13,14,15$.

As evident from the present series accurate preoperative differentiation among three conditions can at times become very challenging even with the help from imaging modalities especially in the setting of a very large swelling and widely dilated deep ring.

Undescended testis with obstructed external ring may be considered as an important etiological factor in our case. Though interparietal hernias have been reported by many authors a combination of poorly developed hemiscrotum6, completely obstructed external inguinal ring with undescended testis along with giant interparietal hernia is a very rare event as only two cases have been reported in last 100 years.

CONCLUSION: A combination of large lower abdominal lump with undescended testis and poorly developed hemiscrotum is a very rare event. Clinical diagnosis is very challenging and diagnostic dilemma persists even with the help of USG and CT scan, as a confident preoperative diagnosis may change drastically intraoperatively. Hence great caution needs to be exercised towards management of patients with such kind of presentation.

\section{BIBLIOGRAPHY:}

1. Mittal T, Kumar V, Khullar R, Sharma A, Soni V, Baijal M, Chowbey PK. Diagnosis and management of Spigelian hernia: a review of literature and our experience. J Minim Access Surg. 2008; 4:95-98.

2. Hojer AM, Rygaard H, Jess P. CT in the diagnosis of abdominal wall hernias: a preliminary study. Eur Radiol 1997;7(9):1416-1418.

3. Loftus IM, Ubhi SS, Rodgers PM, Watkin DF. A negative herniogram does not exclude the presence of a hernia. Ann R Coll Surg Engl 1997;79(5):372-375.

4. Raveenthiran V. Congenital Spigelian hernia and cryptorchidism: probably a new syndrome. Hernia. 2005;9:378-380.

5. Rushfeldt C, Oltmanns G, Vonen B. Spigelian-cryptorchidism syndrome: a case report and discussion of the basic elements in a possibly new congenital syndrome. Pediatr Surg Int 2010;26(9): 939-942.

6. Macready, J.F.C.H.: A Treatise on Ruptures. C. Griffith \& Co., London, 1893.

7. Gobell,R: Uber interparietale Leistenbruche. Deutsche Ztschr. F. Chir., vol. Lvi, pp.1-45, 1900.

8. Lower WE, Hicken NF. Interparietal Hernias. Ann Surg 1931;94(6):1070-1087.

9. Skandalakis PN, Zoras O, Skandalakis JE, et al. Spigelian hernia: surgical anatomy, embryology, and technique of repair. Am Surg 2006; 72:42-48.

10. Rogers FB, Camp PC. A strangulated Spigelian hernia mimicking diverticulitis. Hernia 2001; 5:51-52. 


\section{REVIEW ARTICLE}

11. Singer JA, Mansberger AR Jr. Spigelian hernia. Arch Surg 1973; 107:515.

12. Larson DW, Farley DR. Spigelian hernias: repair and outcome for 81 patients. World J Surg 2002; 26:1277-1281.

13. Zacharakis E, Papadopoulos V, Ganidou M, et al. Incarcerated Spigelian hernia: a case report. Med Sci Monit 2006; 12:CS64-CS66.

14. Campanelli G, Pettinari D, Nicolosi FM, et al. Spigelian hernia. Hernia 2005; 9:3-5.

15. Onal A, Sokmen S, Atila K. Spigelian hernia associated with strangulation of the small bowel and appendix. Hernia 2003; 7:156-157.

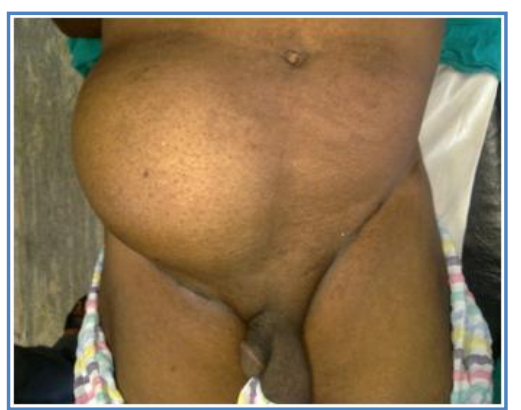

IMAGE-1: Clinical photograph of CASE-1

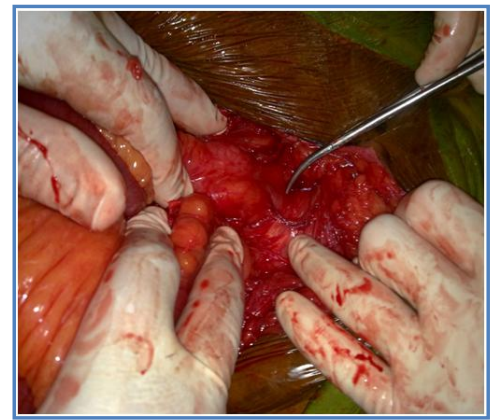

IMAGE-3: Inferior Epigastric Vessels lying Medial to the hernia sac

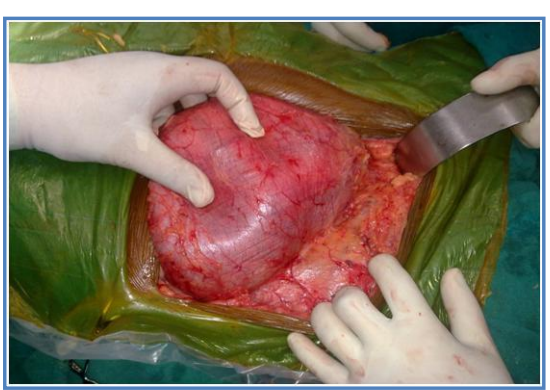

IMAGE-2: Intra-operative thinned out External Oblique Aponeurosis

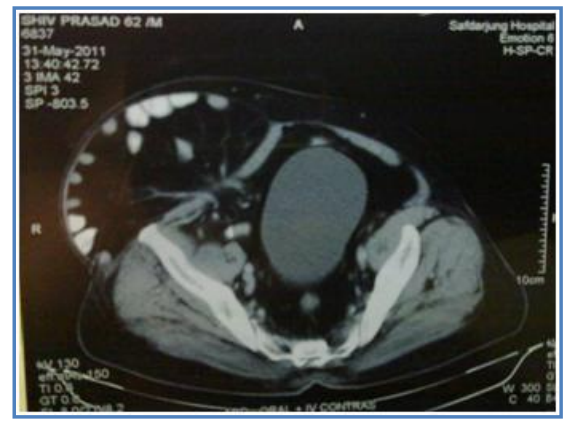

IMAGE-4: CT SCAN of CASE TWO

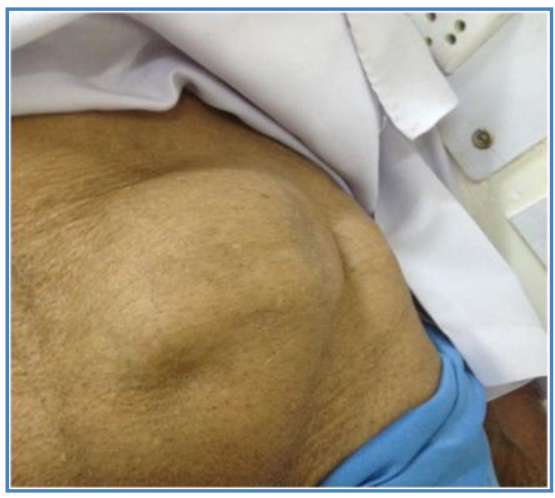

IMAGE-5: Clinical photograph of CASE-2 


\section{REVIEW ARTICLE}

\section{AUTHORS:}

1. Hari Gopal Vyas

2. Mohit Singh

3. Subrato Bhowmick

4. Anuja Swami

5. Vimal Bhandari

6. Pawan Tiwari

\section{PARTICULARS OF CONTRIBUTORS:}

1. Professor and Head, Department of Surgery, SGT Medical College \& Research Institute, Budhera, Gurgaon, Haryana.

2. Assistant Professor, Department of Surgery, RAMA Medical College, Hapur, U.P.

3. Senior Resident, Department of Surgery, V.M.M.C. and Safdarjung Hospi tal, New Delhi.

4. $1^{\text {st }}$ Year Post Graduate, Department of Surgery, SGT Medical College \& Research Institute, Budhera, Gurgaon, Hary ana.
5. Associate Professor and Consultant, Department of Surgery, V.M.M.C. and Safdarjung Hospital, New Delhi.

6. Assistant Professor, Department of Surgery, SGT Medical College \& Research Institute, Budhera, Gurgaon, Haryana.

\section{NAME ADDRESS EMAIL ID OF THE CORRESPONDING AUTHOR:}

Dr. Hari gopal Vyas,

B-304, SGT Campus, SGT Medical College,

Budhera, (Gurgaon), Haryana, PIN - 123505.

Email - premharidpac@yahoo.co.in

Date of Submission: 21/10/2013.

Date of Peer Review: 22/10/2013.

Date of Acceptance: 23/10/2013.

Date of Publishing: 30/10/2013 